\title{
PRODUÇÃO DE MUDAS DE RÚCULA (Eruca sativa) EM FUNÇÃO DE DIFERENTES DOSES DE TORTA DE MAMONA
}

Lorrayne Guimarães Bavaresco ${ }^{1}$, Thadeu Henrique Novais Spósito ${ }^{2}$, Fernando Bernardo Martins ${ }^{1}$, Alline Mendes Alves ${ }^{1}$, Luis Eduardo Vieira Pinto ${ }^{1}$, Rodrigo Bernardo Soldá ${ }^{3}$, Felipe Silva Loosli ${ }^{1}$, Patrícia Rafaella de Mello ${ }^{1}$, Wilton Felipe Teixeira ${ }^{1}$

\footnotetext{
${ }^{1}$ Universidade do Oeste Paulista - UNOESTE, Programa de Pós-Graduação em Agronomia, Presidente Prudente, SP.

¿Universidade Estadual Paulista "Júlio de Mesquita Filho", Programa de Pós-Graduação em Agronomia, Ilha Solteira, SP.

${ }^{3}$ Universidade do Oeste Paulista - UNOESTE, Programa de Residência Agronômica, Presidente Prudente, SP. E-mail: Igbavaresco@hotmail.com
}

\section{RESUMO}

A preparação do substrato na produção de hortaliças é de fundamental importância para obtenção de mudas de alta qualidade. O objetivo deste trabalho foi avaliar o desenvolvimento de mudas de rúcula em diferentes doses de torta de mamona adicionado em substrato. $O$ delineamento experimental foi realizado em blocos casualizados, com cinco doses de torta de mamona $0,10,20,40$ e $80 \mathrm{~g} \mathrm{Kg}^{-1}$ de substrato comercial Bioplant Plus, contendo quatro repetições. Aos 20 dias após a germinação, foram avaliados os parâmetros de crescimento das plantas com a determinação das massas da parte área e do sistema radicular. Para as características analisadas verificou-se o aumento significativo no crescimento vegetativo das plantas em função do incremento das doses de torta de mamona adicionadas ao substrato, sendo este composto orgânico uma alternativa viável para produção de mudas de rúcula.

Palavras-chave: Hortaliças, resíduo industrial, adubo orgânico.

\section{PRODUCTION OF ROCKET SEEDLINGS (Eruca sativa) IN THE FUNCTION OF DIFFERENT DOSES OF MAMONA CAKE}

\begin{abstract}
The preparation of the substrate in the production of vegetables is of fundamental importance to obtain seedlings of high quality. The objective of this work was to evaluate the development of rocket seedlings in different doses of castor bean cake added in substrate. The experiment was carried out in a randomized complete block design with five replicates of $0,10,20,40$ and $80 \mathrm{~g} \mathrm{Kg}$ 1 of Bioplant Plus commercial substrate containing four replicates. At 20 days after germination, the parameters of plant growth were evaluated with determination of the masses of the area and the root system. For the analyzed characteristics, it was verified the significant increase in the vegetative growth of the plants as a function of the increment of the doses of castor bean added to the substrate, being this organic compound a viable alternative for the production of rocket seedlings.
\end{abstract}

Keywords: Vegetable crops, Industrial waste, organic fertilizer.

\section{INTRODUÇÃO}

A rúcula (Eruca sativa) é uma hortaliça folhosa herbácea de rápido crescimento vegetativo e ciclo curto, que vem conquistando espaço no mercado brasileiro, com aumento na quantidade comercializada e área de plantio, estando entre as hortaliças mais nutritivas e ricas em minerais e vitaminas (ENSINAS et al. ,2008; LOPES et al., 2017). 
O sucesso do cultivo de hortaliças depende em grande parte da utilização de mudas de alta qualidade, uma vez que ela influência o desempenho final das plantas nos canteiros de produção (CARMELLO, 1995). O substrato é um componente que exerce a função do solo, sendo de grande importância no processo de formação de mudas, principalmente nas fases iniciais do desenvolvimento da plântula, fornecendo sustentação, água, nutrientes e oxigênio (RODRIGUES; COSTA, 2009).

As propriedades dos substratos são variáveis em função de sua origem, método de produção ou obtenção e proporção de seus componentes, não existindo, portanto, um material ou uma mistura de materiais considerada universal para utilização em todas as espécies (KLEIN, 2015). Desta forma, é necessário verificar experimentalmente, para cada espécie vegetal, qual o substrato ou a melhor mistura de substratos que permite a formação de mudas de qualidade em diferentes ambientes de produção (SANTOS et al., 2005).

A qualidade do substrato é resultante da combinação de materiais com características químicas e físicas adequadas, as necessidades da espécie cultivada (SEVERINO et al. 2006). De modo geral, um bom substrato deve apresentar: capacidade de retenção de água suficiente para geminação e manutenção das plântulas, proporcionar boa aeração permitindo a difusão de oxigênio para as raízes, baixa resistência à penetração das raízes, ser isento de patógenos, disponibilidade de nutrientes essenciais, $\mathrm{pH}$ adequado, textura média e agregados estáveis (SILVA et al., 2009).

A utilização de resíduos agroindustriais como componentes de substratos hortícolas vem se apresentando como alternativa potencialmente vantajosa, de fácil e constante disponibilidade a baixo custo, auxiliando na minimização da poluição decorrente do acúmulo de resíduos no ambiente (SCHMITZ; SOUZA; KÄMPF, 2002).

A torta de mamona é um resíduo industrial produzido durante o processo de extração de óleo das sementes da mamoneira (Ricinus comunis) com elevado teor de nitrogênio, podendo ser utilizado como fonte de nutrientes quando misturado ao substrato (MARTINS et al. 2011). Por ser um material orgânico, a liberação de nutrientes para as plantas não ocorre tão rapidamente quanto a de fertilizantes químicos, porém quando comparada a outros resíduos orgânicos como esterco bovino e bagaço de cana, a torta de mamona demonstra rápida velocidade de mineralização (SEVERINO, 2005; SEVERINO et al., 2004).

Além de servir como fonte nitrogenada e de macronutrientes, a torta de mamona também tem sido relacionada à redução da população de fitonematoides e de insetos pragas, pela liberação de elementos tóxicos durante a sua decomposição (SAMPAIO et al., 2009; SEVERINO, 2005). O objetivo deste trabalho foi avaliar o desenvolvimento de mudas de rúcula em diferentes doses de torta de mamona adicionado em substrato.

\section{METODOLOGIA}

O experimento foi conduzido em casa de vegetação no setor de horticultura da ETEC Escola Técnica Prof. Dr. Antonio Eufrásio de Toledo, Presidente Prudente-SP, no período de outubro a novembro de 2016. O delineamento experimental foi realizado em blocos casualizados (DBC), com cinco tratamentos e quatro repetições.

As mudas foram produzidas em bandejas de poliestireno expandido de 200 células, com utilização de substrato comercial Bioplant Plus, indicado para produção de mudas de hortaliças, constituído por fibra e pó de coco, casca de pinus, vermiculita, casca de arroz e nutrientes. A torta de mamona utilizada foi adquirida em comércio, marca Vitaplan, cuja composição química fornecida pelo fabricante é de $5 \%$ de Nitrogênio e 35\% de carbono, contendo pH 6. 
A torta de mamona foi incorporada ao substrato nas dosagens: 0, 10, 20, 40 e $80 \mathrm{~g} \mathrm{Kg}^{-1} \mathrm{de}$ substrato. Após a adição e homogeneização da torta de mamona, o substrato foi umedecido e depositado sobre a bandeja, em parcelas contendo 20 células (unidades experimentais), com semeadura de quatro a seis sementes de rúcula cultivar Folha Larga por célula, na profundidade de um centímetro. As bandejas foram dispostas sobre suportes a $50 \mathrm{~cm}$ do solo, acondicionadas em casa de vegetação, com irrigação realizada manualmente de maneira a manter o substrato sempre úmido. Após a emergência foi realizado o desbaste deixando três plântulas por célula.

As avaliações foram efetuadas aos 20 dias após a geminação das plantas, e os parâmetros avaliados foram: massa fresca da parte aérea (MFPA), massa fresca das raízes (MFR), massa seca da parte aérea (MSPA) e massa seca das raízes (MSR). A partir destes dados foram calculados a massa fresca total (MFT), a massa seca total (MST) e a razão entre a massa seca da parte aérea e a massa seca das raízes (RPAR).

Para determinação das pesagens realizou-se a coletada de 20 mudas por repetição que foram levadas ao laboratório, onde as raízes foram lavadas para remoção do substrato, separando-se a parte aérea do sistema radicular. A massa fresca da parte aérea e do sistema radicular foram obtidos através de uma balança de precisão, e logo depois os materiais foram acondicionados separadamente em sacos de papel e mantidos em estufa a $65{ }^{\circ} \mathrm{C}$ até atingirem peso constante para a determinação da massa seca da parte aérea e da raiz.

Os dados obtidos foram submetidos à análise de variância e as médias submetidas a análise de regressão a 5\% de probabilidade. A avaliação estatística do experimento foi realizada em programa computacional SISVAR Sistema para Análise de Variância (FERREIRA, 2000).

\section{RESULTADOS}

Para as características analisadas de massa fresca da parte aérea, massa fresca das raízes, massa seca das raízes, massa fresca total e massa seca total, verificou-se uma resposta linear crescente das plantas de rúcula em função do incremento das doses de torta de mamona adicionadas ao substrato (Figura 1).

Com relação à massa seca da parte aérea das plantas de rúcula, a análise de regressão demonstrou uma equação quadrática, atingindo o ponto de máxima produção na dose de $49 \mathrm{~g}$ de torta de mamona $\mathrm{Kg}^{-1}$ de substrato, alcançando um valor de 0,166 $\mathrm{g}^{-1}$ muda. Para razão entre a massa seca da parte aérea e a massa seca das raízes não houve efeito significativo das doses de torta de mamona testadas. 
FIGURA 1. Efeito de doses de torta de mamona adicionadas ao substrato para produção de mudas de rúcula, cv. Folha Larga na massa fresca da parte aérea (MFPA) (A), massa fresca das raízes (MFR) (B), massa seca da parte aérea (MSPA) (C), e massa seca das raízes (MSR) (D), massa fresca total (MFT) (E), a massa seca total (MST) (F).
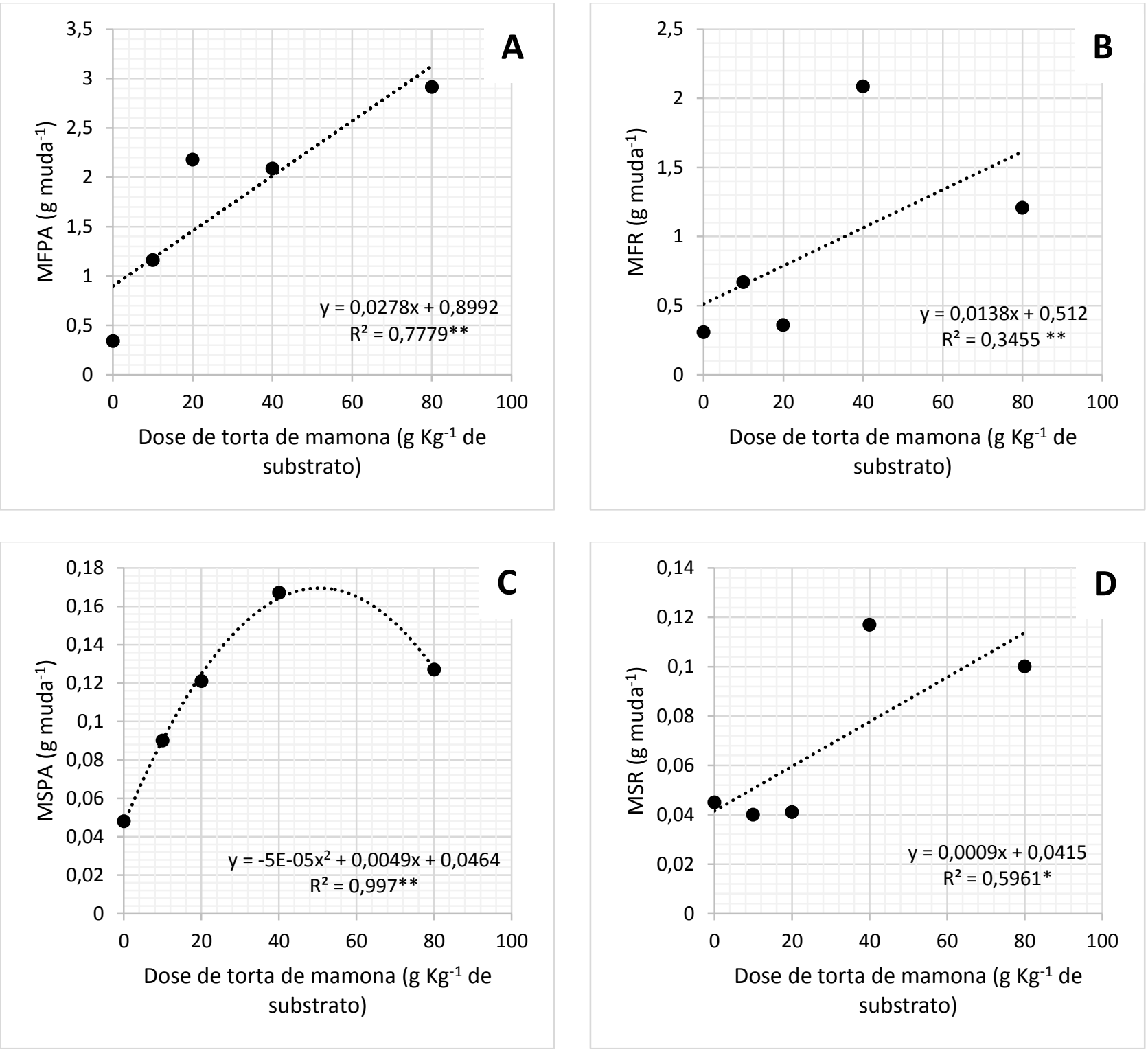

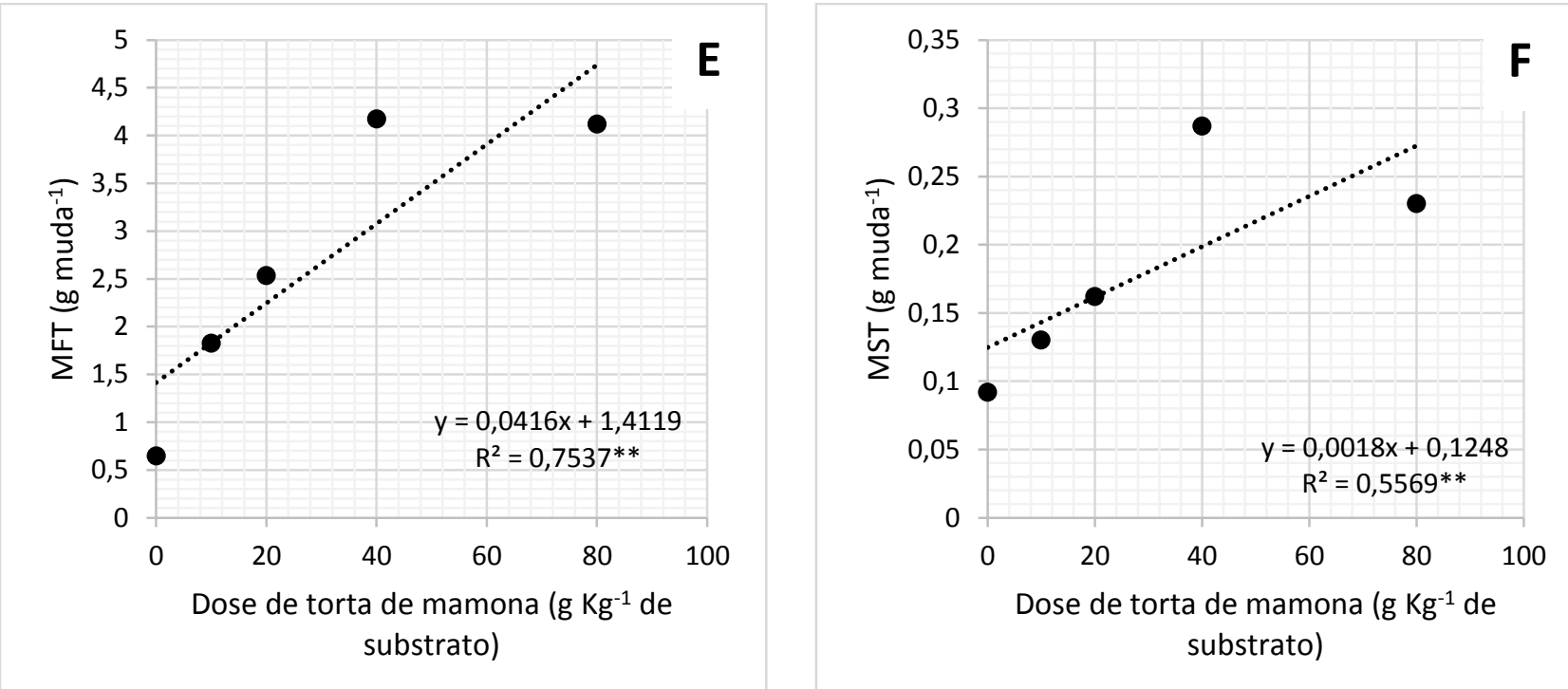

${ }^{*} \mathrm{e}^{* *}$ significativo a $5 \%$ e $1 \%$ de probabilidade, respectivamente.

Além dos parâmetros avaliados durante o experimento foi observado que o número de plântulas emergidas não foi afetado pelas diferentes doses utilizadas de torta de mamona, ocorrendo $100 \%$ de germinação das sementes, evidenciando que não houve caráter fitotóxico no desenvolvimento das mudas de rúcula.

\section{DISCUSSÃO}

A torta de mamona apresenta boas características para uso como adubo orgânico, principalmente devido ao alto teor de nitrogênio (LIMA et al., 2008). Esta afirmação justifica os resultados positivos em relação ao aumento de crescimento da parte aérea e radicular das plantas de rúcula, uma vez que o nitrogênio é um elemento essencial para produção de compostos estruturais, genéticos e metabólicos nas células vegetais, cuja ausência ou deficiência é um fator limitante para o desenvolvimento de plantas.

Lima et al. (2008), assim como neste experimento, também encontraram diferenças significativas, com efeito linear para as doses avaliadas de torta de mamona $(0,5 ; 1,0 ; 1,5$ e 2,0 t/ha), influenciando positivamente as variáveis de crescimento de plantas de mamona cultivadas em vaso.

De acordo com Severino et al. (2004), a torta de mamona é um material orgânico de rápida decomposição, assim a liberação e disponibilidade de nutrientes para as plantas ocorre em curto espaço de tempo e de modo gradual, refletindo rapidamente no crescimento vegetativo de plantas. Leal et al. (2009), estudando o enriquecimento de composto orgânico para produção de hortaliças, verificaram maior produção de massa fresca e de massa seca, quando adicionados ao substrato níveis de $2 \% \mathrm{v} / \mathrm{v}$ de torta de mamona, melhorando o desempenho de mudas de alface, beterraba e tomateiro.

Resultados semelhantes foram observados por Oliveira et al. (2010), na produção de mudas de berinjela adicionando $2 \%$ de torta de mamona em substrato orgânico. No entanto, estes mesmos autores constataram que concentrações superiores a $2 \%$ são prejudiciais a esta cultura, chegando a afetar negativamente o percentual de emergência, além de desacelerar de modo significativo o crescimento das plantas. A explicação para estes efeitos deletérios, segundo estes autores, está relacionada à fitotóxidez causada pela condutividade elétrica excessiva do material orgânico, tendo em vista que altos níveis de sais são encontrados na torta de mamona. 
Gouzalez, et al. (2006), concluíram que substratos elaborados a base de torta de mamona não mostraram resultados satisfatórios para a produção de mudas de tomate, atribuindo este resultado a existência de alguma substância tóxica contida na torta de mamona ou ao aumento de temperatura no substrato causado pela fermentação decorrente do processo de decomposição da mesma, que foi usada sem passar por nenhum tipo de compostagem.

\section{CONCLUSÃO}

As doses de torta de mamona propostas neste experimento proporcionaram o aumento do crescimento vegetativo das plantas, demostrando ser uma alternativa viável para o enriquecimento de substratos para produção de mudas de rúcula.

\section{REFERÊNCIAS}

CARMELLO Q. A. C. Nutrição e adubação de mudas hortícolas. In: MINAMI, K. Produção de mudas de alta qualidade em horticultura. São Paulo: T.A. Queiroz, p. 27-37, 1995.

ENSINAS S. C. et al. Níveis de fertirrigação nas características morfofisiológicas de mudas de rúcula. Agrarian, v.2, n.3, jan./mar. 2009.

FERREIRA, D. F. Análises Estatísticas por meio do Sisvar para Windows versão 4.0 IN. 45a Reunião anual da Região Brasileira da Sociedade Internacional de Biometria. UFSCAR, São Carlos, SP. Julho de 2000. p. $255-258$.

GOUZALEZ R. G.; et al. Utilização de torta de mamona em substratos para produção de mudas de tomate. In: CONGRESSO DE BIODIESEL, 2006. Brasília. Anais... Brasília: Embrapa, 2006. p.140-142.

KLEIN C. Utilização de substratos alternativos para produção de mudas. Revista Brasileira de Energias Renováveis, v.4, p. 43-63, 2015. https://doi.org/10.5380/rber.v4i3.40742

LEAL M. A. A. et al Diferentes níveis de enriquecimento de composto orgânico visando sua utilização como substrato para produção de mudas de hortaliças. Embrapa Agrobiologia, Boletim de Pesquisa \& Desenvolvimento, n. 58. 20 p. Seropédica, RJ, 2009.

LIMA R. L. S et al.Casca e torta de mamona avaliados em vasos como fertilizantes orgânicos Caatinga, Mossoró, v.21 n.5 (Número Especial), p.102-106, dez.2008.

LOPES M. C. et al. Efeito da aplicação foliar de biofertilizante na produção de mudas de rúcula sob diferentes substratos. Nucleus, v.14,n.1,abr.2017.

MARTINS A. N. et al. Adição de torta de mamona em substratos na aclimatação de mudas micropropagadas de bananeira. Rev. Bras. Frutic. v.33, n.1, Jaboticabal, 2011.

OLIVEIRA E. A. G. et al. Enriquecimento nutricional com torta de mamona na formulação de substrato orgânico para produção de mudas de berinjela. VII ENSub, Goiânia, Goiás, set. 2010.

RODRIGUES V. A.; COSTA, P. N. Análise de diferentes de substratos no crescimento de mudas de seringueira. Revista científica eletrônica de engenharia florestal, Ano VIII, n.14, Ago. 2009. 
SAMPAIO A.H. et al. Controle de fitonematoides em aceroleira mediante o uso de farelo de mamona. 2ㅇ Congresso Brasileiro de mamona, 2009. Disponível em: http://www.cnpa.embrapa.br/produtos/mamona/publicacoes/trabalhos cbm2/042.pdf Acessado em 31 de jul. 2017.

SANTOS A. C. P. et al. Utilização de torta de filtro como substrato para a produção de mudas de hortaliças. Colloquium Agrariae, v. 1, n.2, p.5. dez. 2005. https://doi.org/10.5747/ca.2005.v01.n2.a007

SCHMITZ J. A. K.; SOUZA P. V. D.; KÄMPF A. N. Propriedades químicas e físicas de substratos de origem mineral e orgânica para o cultivo de mudas em recipientes. Cienc. Rural vol.32 n.6 Santa Maria Dez. 2002.

SEVERINO L. S. O que sabemos sobre a torta de mamona. Campina Grande, Embrapa algodão, Documento 134, 31 p. 2005.

SEVERINO L. S. et al. Mineralização da torta de mamona, esterco bovino e bagaço de cana estimada pela respiração microbiana. Revista de Biologia e Ciências da Terra, Campina Grande, v. 5, n. 1, 2004.

SEVERINO L.S. et al. Composição Química de Onze Materiais Orgânicos Utilizados em Substratos para Produção de Mudas. Ministério da Agricultura, Pecuária e Abastecimento - Comunicado Técnico 278, Campina Grande, PB. Embrapa Algodão 5p. ago. 2006.

SILVA, L. J. B. da et al. Produção de mudas de rúcula em bandejas com substratos a base de resíduos orgânicos. Ciênc. agrotec., Lavras, v. 33, n. 5, p. 1301-1306, set./out., 2009. 